\title{
VALUASI EKONOMI EKOSISTEM MANGROVE DI DESA PASAR NGALAM KABUPATEN SELUMA
}

\author{
Oleh \\ Jenny Rospita, Zamdial, Person Pesona Renta, \\ Program Studi Ilmu Kelautan, Fakultas Pertanian Universitas Bengkulu, \\ Bengkulu \\ Email: jrozpita.220194@gmail.com \\ Received February 2017 Accepted March 2017
}

\begin{abstract}
ABSTRAK
Penelitian ini bertujuan untuk menghitung dan menganalisis valuasi ekonomi mangrove di Desa Pasar Ngalam Kabupaten Seluma. Penelitian dilaksanakan di Desa Pasar Ngalam Kecamatan Air Periukan Kabupaten Seluma. Waktu penelitian dilaksanankan pada bulan Agustus - September 2016, adapun metode penelitian yang digunakan adalah metode survei dan metode wawancara. Kondisi perairan ekosistem mangrove di Desa Pasar Ngalam masih dalam kondisi yang baik. Manfaat dari ekosistem mangrove di Desa Pasar Ngalam Kabupaten Seluma terdiri dari manfaat langsung yaitu kegiatan perikanan tangkap, manfaat tidak langsung berupa penghalang terhadap abrasi pantai, manfaat pilihan berupa manfaat keanekaragaman hayati, dan manfaat eksistensi berupa WTP. Nilai Total Ekonomi dari ekosistem mangrove di Desa Pasar Ngalam Kabupaten Seluma sebesar Rp719.805.999,-/per tahun, yang terdiri dari nilai manfaat langung sebesar Rp328.692.000,- per tahun (45,39\%), manfaat tidak langsung sebesar Rp386.291.010,-/tahun (53,32\%), nilai manfaat pilihan sebesar Rp1.522.989,- per tahun (0,21\%), dan nilai keberadaan sebesar Rp3.300.000,- per tahun $(0,45)$.
\end{abstract}

Kata Kunci: Valuasi Ekonomi, Mangrove, Desa Pasar Ngalam.

\section{ABSTRACT}

The aims of this research were to quantifyed and analyzed the economic valuation of mangroves in Pasar Ngalam Bengkulu Province.This Research conducted at August - September 2016. Survey and interview method were used on this research. The mangrove condition of the location was in good condition. There are four benefits of mangrove ecosystems at Pasar Ngalam Village, which is direct benefits (fisheries), indirect benefits (as barrier of abrasion), option benefits (biodiversity), and existence benefits (willing to pay). The result found that total economic value of the mangrove ecosystem was Rp. 719.805.999,-/year, included the value of direct benefits was Rp. 328.692.000,/year (45.39\%), the value of indirect benefits was Rp. 386.291 .010 ,-/year $(53.32 \%)$, the value of option benefits was $\mathrm{Rp} .1 .522 .989,-/$ year $(0.21 \%)$, and the value of existence benefits was Rp. 3.300.000,-/year (0.45).

Keywords: Economic Valuation, Mangrove, Pasar Ngalam Village. 


\section{PENDAHULUAN}

Ekosistem mangrove adalah hutan yang tumbuh di daerah pasang surut, terutama di pantai yang terlindung dan muara sungai yang tergenang pada saat pasang dan bebas dari genangan pada saat surut serta komunitas tumbuhannya bertoleransi terhadap garam. Menurut FAO, Hutan Mangrove adalah Komunitas tumbuhan yang tumbuh di daerah pasang surut. Kondisi habitat tanah berlumpur, berpasir, atau lumpur berpasir. Ekosistem tersebut merupakan ekosistem yang khas untuk daerah tropis dan sub tropis, terdapat di derah pantai yang berlumpur dan airnya tenang.

Ekosistem mangrove merupakan salah satu sumberdaya alam wilayah pesisir yang mempunyai peran penting ditinjau dari sudut ekologi, dan sosial ekonomi. Fungsi ekologi sebagai penyeimbang ekosistem dan penyedia berbagai kebutuhan hidup lainnya. Hutan mangrovemerupakan tempat pemijahan (spawning ground), daerah asuhan (nursery ground), dan daerah untuk mencari makan (feeding ground) bagi ikan dan biota laut lainnya. Mangrove juga berfungsi untuk menahan gelombang laut dan intrusi air laut kearah darat (Kusmana, 2009). Dari segi ekonomi, hutan mangrove menghasilkan beberapa jenis kayu yang berkualitas baik, dan juga hasil-hasil non-kayu barupa arang kayu, bahan pewarna dan kosmetik, serta bahan pangan dan minuman. Termasuk pula diantaranya adalah hewan-hewan yang bisa ditangkap seperti biawak air (Varanus salvator), kepiting bakau (Scylla serrata), udang lumpur (Thalassina anomala), siput bakau (Telescopium telescopium), serta berbagai jenis ikan.

Pemanfaatan terhadap ekosistem mangrove secara terus menerus memberi konsekuensi bagi ekosistem hutan mangrove itu sendiri, yaitu dengan semakin tingginya tingkat eksploitasi terhadap lingkungan yang tidak jarang berakhir pada degradasi lingkungan yang cukup parah.Sampai saat ini, kebanyakanmanusia khususnya para perencana danpengambil keputusan menghargai nilaimanfaat ekosistem alamiah hanya dari segi manfaat langsung (direct-usevalue), padahal Nilai Ekonomi Totalsuatu ekosistem alamiah terdiri dari nilaipenggunaan (use-value) dan nilai bukanpenggunaan (non-use value), sehinggamereka memberikan penilaian yangrendah terhadap keberadaan ekosistemmangrove. Oleh sebab itu, begitu mudahmereka mengkonversi ekosistemalamiah mangrove menjadi peruntukan lain (Dahuri, 2003dalam Zen, 2013).

Pasar Ngalam termasuk dalam wilayah Kecamatan Air Periukan, Kabupaten Seluma, Provinsi Bengkulu dan wilayah kerja pengelolaan kawasan masuk dalam seksi konservasi wilayah II Seluma. Cagar alam Pasar Ngalam

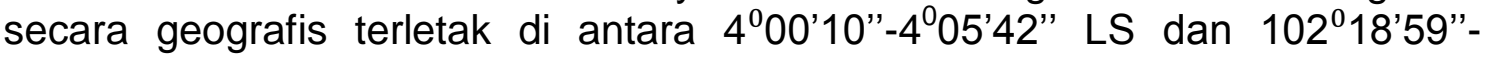
$102^{\circ} 25^{\prime} 00^{\prime \prime} B T$. Hutan Suaka Alam (HSA) Pasar Ngalam ditunjuk pertama kali oleh Menteri Kehutanan pada tahun 1985, berdasarkan Surat Keputusan Menteri Kehutanan Nomor: 383/Kpts-II/1985 tanggal 27 Desember 1985 tentang penunjukan kawasan hutan di Wilayah Tingkat I Bengkulu seluas \pm 1.157.045 ha sebagai Kawasan Hutan. Hutan Suaka Alam Pasar Ngalam memiliki luas $\pm 256,92$ ha,dengan panjang batas $14,037 \mathrm{~km}$. Pada tahun 1995 dilakukan pembuatan batas sementara dan pembuatan batas definitif tahun 1996. Tahun 1997 dilakukan penegasan batas kawassan melalui orintasi batas 
dan rekonstruksi batas kawasan dengan panjang batas8,4 km. Pada tahun 1999, melalui surat keputusan menteri kehutanan nomor: 420/Kpts-II/1999 tanggal 15 juni 1999 tentang penunjukan kawasan hutan di wilayah Provinsi Bengkulu seluas 920,96 ha. Hutan Suaka Pasar Ngalam ditunjuk sebagai kawasan hutan dengan luas 256,92 ha(BKSDA Bengkulu, 2016)

Penilaian ekonomi dari ekosistem mangrove di Desa Pasar Ngalam perlu dilakukan karena dapat memberikan gambaran tentang nilai ekonomi ekosistem mangrove di Desa Pasar Ngalam tersebut.Hasil penelitian ini diharapkan dapat menjadi dasar untuk merumuskan strategi pengelolaan hutan mangrove yangberkelanjutan dengan tetap memperhatikan aspek fungsi dan peran mangrove.

\section{Tujuan dan Manfaat Penelitian}

Penelitian ini bertujuan untuk menghitung dan menganalisis valuasi ekonomi ekosistem mangrove di Desa Pasar Ngalam Kabupaten Seluma.

Manfaat dari penelitian ini adalah sebagai dasar dalam upaya pemanfaatan dan pengelolaan ekosistem mangrove oleh masyarakat setempat. Penelitian ini diharapkan dapat dijadikan sebagai bahan masukan bagi para pengambil kebijakan dalam perencanaan dan pengelolaan sumberdaya mangrove serta mendorong peningkatan peran serta masyarakat dalam menjaga kelestarian ekosistem mangrove sebagai kawasan yang produktif.

\section{MATERI DAN METODE}

\section{Waktu dan Tempat}

Penelitian ini dilakukan di Desa Pasar Ngalam Kabupaten Seluma. Waktu penelitian pada bulan Agustus-September 2016.

\section{Alat dan Bahan}

Alat dan bahan yang digunakan adalah sebagai berikut : Tabel 1. Alat dan Bahan Penelitian

\begin{tabular}{ll}
\hline \multicolumn{1}{c}{ Nama Alat \& Bahan } & \multicolumn{1}{c}{ Fungsi } \\
\hline Kamera digital & Dokumentasi gambar di lapangan \\
Alat tulis & Pencatatan data lapangan \\
pH Meter & Mengukur pH perairan \\
Termometer & Mengukur suhu perairan \\
Refraktometer & Mengukur Salinitas \\
Daftar pertanyaan & Mencari data dan informasi dari masyarakat \\
kuesioner & \\
GPS & Menentukan titik koordinat lokasi penelitian \\
Air tawar dan tissue & Membersihkan alat penelitian \\
\hline
\end{tabular}

\section{Penentuan Data Penelitian}

Data yang diperlukan pada penelitian ini adalah data primer dan data sekunder. Menurut Umar (2003), data primer dapat didefenisikan sebagai data yang diperoleh langsung dari subyek penelitian dengan mengenakan alat pengukuran atau alat pengambilan data langsung pada subjek sebagai sumber 
informasi yang dicari. Adapun data sekunder adalah data yang diperoleh lewat pihak lain, tidak langsung diperoleh oleh peneliti dari subjek penelitiannya (Sugiono,2005).

Data primer yang perlukan dalam penelitian ini adalah data karakteristik biofisik ekosistem hutan mangrve yaitu

1. Data Parameter kualitas air ekosistem mangrove yang meliputi : suhu, $\mathrm{pH}$, salinitas, oksigen terlarut,

2. Data kuisioner.

Data sekunder yang diperlukan dalam penelitian ini adalah sebagai berikut :

1. Struktur vegetasi mangrove : kerapatan, frekuensi, dominasi, indeks nilai penting,

2. Parameter biologi yang meliputi : tegakan vegetasi mangrove,

3. Data demografi : jumlah penduduk, pekerjaan, umur, pendidikan, dll

4. Data pendukung lainnya yang dianggap penting.

Data sekunder sebagai pendukung dan pembanding diperoleh dari berbagai instansi pemerintah, dan kelompok tani yang mempunyai keterkaitan dengan pemafaatan dan pengelolaan ekosistem mangrove.

\section{Metode Pengambilan Data}

Penelitian ini dilakukan dengan metode survei yaitu kegiatan observasi dan pengukuran langsung untuk mendapatkan data parameter kualitas air ekosistem hutan mangrove. Untuk data sosial-budaya, potensi ikan dan nonikan, dan penentuan nilai ekonomi ekosistem hutan mangrove diperlukan sampel yang ditetapkan dengan menggunakan metode wawancara terstruktur dan tidak terstruktur terhadap sampel/responden yang telah ditetapkan dengan cara mengambil subjek didasarkan atas adanya tujuan tertentu dari penelitian yang dilakukan. Berdasarkan syarat-syarat pengambilan sampel, maka diambil beberapa responden dari : 1) pecari ikan, 2) pencari kepiting, 3) pencari udang, 4) pemangku kepentingan yaitu pemerintah, kelompok tani dan kelompok masyarakat yang mengelola ekosistem hutan mangrove, yang diwakili oleh pengurus kelompok dan petugas khusus yang ditunjuk dan unsur dari pemerintah desa. Dalam penelitian ini, jumlah responden yang ditentukan sebanyak 40 responden.

\section{Analisis Data Penelitian}

Data yang diperoleh akan dianalisa secara deskriptif kuantitatif yaitu menganalisis data dengan melihat nilai besarnya dalam bentuk nilai rata-rata dan akan disajikan dalam bentuk tabel dan gambar.

\section{Perhitungan Nilai Ekosistem Mangrove}

Perhitungan nilai ekosistem mangrove dapat diidentifikasikan dari berbagai manfaat dan fungsi ekosistem hutan mangrove, yaitu :

a. Nilai manfaat langsung

DUV $=\sum$ DUVi (dimasukkan kedalam nilai rupiah)
Dimana :
DUV = Manfaat langsung
DUV $1=$ Manfaat langsung kepiting


DUV 2 = Manfaat langsung ikan

DUV 3 = Manfaat langsung udang

b. Manfaat tidak langsung

IUV = IUVe (dimasukkan kedalam nilai rupiah)

Dimana :

IUV = manfaat tidak langsung

IUVe = manfaat tidak langsung sebagai peredam gelombang (breakwater)

c. Manfaat pilihan (option value)

OV $=$ US $\$ 15$ per ha/tahun $\times$ luas hutan mangrove

Dimana : OV = manfaat pilihan

d. Manfat keberadaan (Exsistence)

$$
\mathrm{EV}=\sum_{i=1}^{n}(\mathrm{EVi}) / \mathrm{n}
$$

Dimana :

$\mathrm{EV} \quad=$ Manfaat Eksistensi

Evi = manfaat eksistensi responden $\mathrm{ke}-\mathrm{i}$

$\mathrm{N} \quad=$ jumlah contoh atau responden

Teknik perhitungan untuk menilai ekonomi suatu sumber daya, mengacu metode valuasi ekonomi atau Total Ekonomi Valuation (TEV) yang dikemukakan oleh Dixon et al, (1988) dalam Pomeroy (1992). Secara matemetis dapat dirumuskan dalam persamaan sebagai berikut :

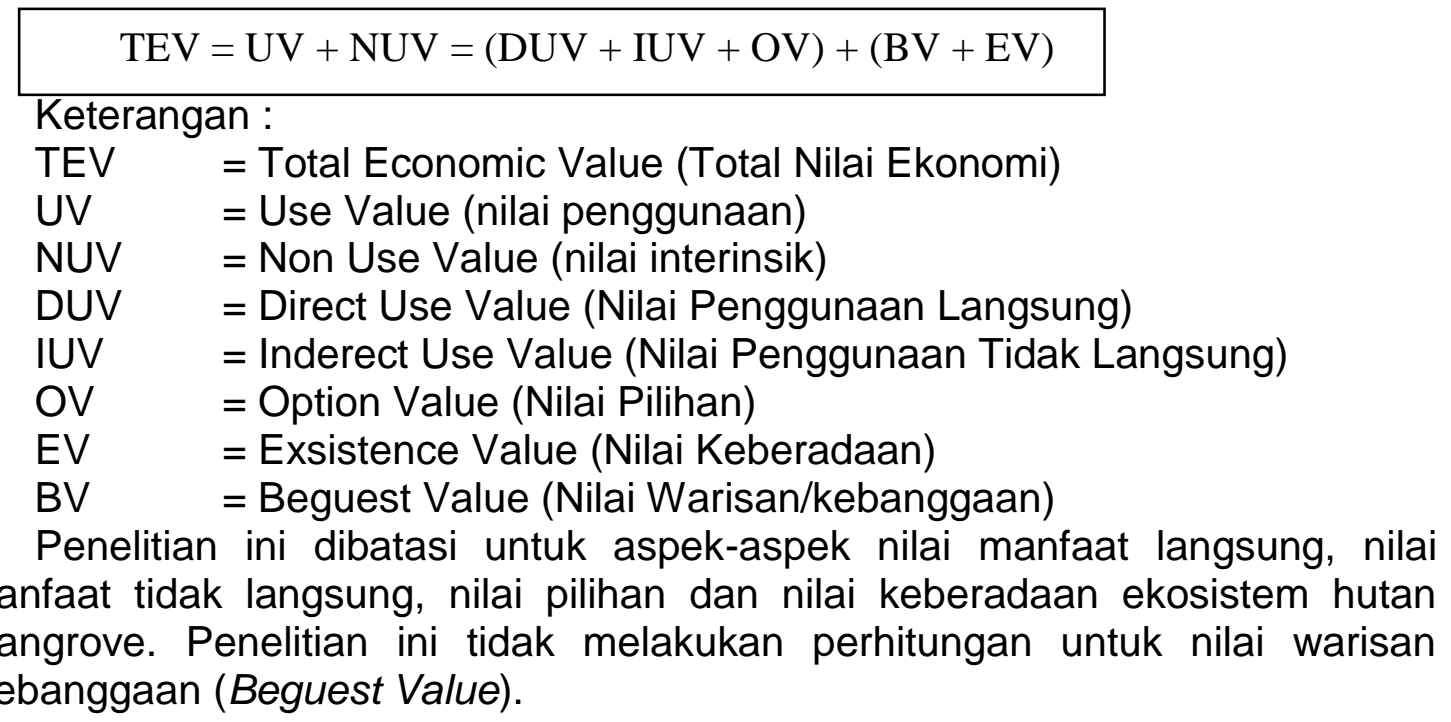

\section{HASIL DAN PEMBAHASAN}

\section{Keadaan Umum Lokasi Penelitian}

Berdasarkan peraturan Desa Pasar Ngalam, Desa Pasar ngalam Memiliki luas wilayah lebih kurang 9.800 Ha. Desa Pasar Ngalam merupakan desa yang secara administratif berada di wilayah Kecamatan Air Periukan Kabupaten Seluma Provinsi Bengkulu. Desa Pasar Ngalam berbatasan dengan: 
a. Sebelah utara berbatasan dengan Desa Suka Sari,

b. Sebelah selatan berbatasan dengan Desa Pasar Seluma,

c. Sebelah timur berbatasan dengan Desa Keban Angung,

d. Sebelah barat berbatasan dengan Desa Kungkai Baru.

\section{Keadaan Sosial}

Berdasarkan data yang diperoleh dari profil Desa Pasar Ngalam pada Tahun 2015 menunjukkan bahwa penduduk Desa Pasar Ngalam 90\% terdiri dari masyarakat asli serawai, dan lainnya sebanyak 10\%. Desa Pasar Ngalam mempunyai jumlah penduduk 1.882 jiwa, yang terdiri dari laki-laki 1.006 orang dan perempuan 876 orang yang terdiri dari 486 KK. Dapat dilihat pada tabel 2 dan presentase dapat dilihat pada gambar 2 .

Tabel 2. Jumlah Penduduk Brdasarkan Jenis Kelamin.

\begin{tabular}{cc}
\hline Jenis kelamin & Jumlah jiwa \\
\hline Pria & 1006 \\
Wanita & 876 \\
\hline
\end{tabular}

Sumber: Kantor Desa Pasar Ngalam (2016)

Mata pencaharian yang ada di Desa Pasar Ngalam meliputi petani, peternak, nelayan, pedagang, usaha kecil, PNS dan buruh. Mata pencaharian yang paling mendominasi di Desa Pasar Ngalam ialah petani yang berjumlah sebnyak 260 orang, selanjutnya yang bermata pencaharian buruh sebanyak 150 orang, peternak dan nelayan sebanyak 118 orang, usaha kecil sebanyak 87 orang, pedagang sebanyak 42 orang dan PNS sebanyak 9 orang dapat dilihat pada tabel 4 dan persentase mata pencaharian masyarakat Desa Pasar Ngalam dapat dilihat pada gambar 4 .

\section{Gambaran Umum Ekosistem Mangrove Di Desa Pasar Ngalam Kabupaten Seluma}

\section{Kondisi Ekosistem Mangrove}

Ekosistem hutan mangrove yang berada di desa Pasar Ngalam Kabupaten Seluma memiliki luas sekitar 7,8 hektar (Google Earth, 2016). Selama ini tidak ada peran serta pemerintah maupun masyarakat dalam pengelolaan ekosistem mangrove di Desa Pasar Ngalam tersebut, sehingga kondisi ekosistem mangrove mengalami penurunan dikarenakan adanya Ancaman kerusakan ekosistem mangrove, yakni adanya masyarakat yang melakukan konversi lahan menjadi lahan perkebunan kelapa sawit.

Adapun hasil wawancara mengenai perubahan ekosistem mangrove terlihat pada Tabel 3, sedangkan Persentase mengenai penurunan dan kerusakan mengrove menurut beberapa responden dapat dilihat pada gambar 3.

Tabel 3. Penurunan dan kerusaka mangrove di Desa Pasar Ngalam

\begin{tabular}{cccc}
\hline \multirow{2}{*}{$\begin{array}{c}\text { Perubahan kondisi } \\
\text { ekosistem }\end{array}$} & \multicolumn{2}{c}{ Responden } & \\
\cline { 2 - 3 } mangrove & Nelayan & Non nelayan & Persentase \\
\hline Meningkat & 0 & 0 & 0 \\
Menurun & 15 & 13 & $71 \%$ \\
tidak tau & 8 & 4 & $29 \%$ \\
\hline
\end{tabular}




\section{persentase perubahan mangrove}

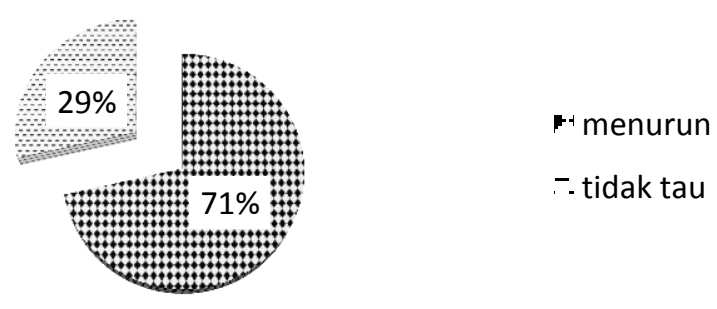

Gambar 1. Persentase Perubahan Mangrove Persepsi Responden

Dari persentase perubahan mengrove menurut persepsi responden di atas bahwa responden beranggapan ekosistem mangrove di Desa Pasar Ngalam mengalami penurunan dan ditunjukkan persentase sebesar $71 \%$ dan sebesar $29 \%$ responden tidak mengetahui perubahan kondisi ekosistem mangrove, dapat dilihat pada Tabel 4.

Tabel 4. Kondisi ekosistem mangrove

\begin{tabular}{|c|c|c|c|}
\hline \multirow{2}{*}{$\begin{array}{c}\text { Kondisi ekosistem } \\
\text { mangrove }\end{array}$} & \multicolumn{3}{|c|}{ Respondem } \\
\hline & Nelayan & Non nelayan & \\
\hline baik & 5 & 8 & \\
\hline sedang & 13 & 7 & \\
\hline rusak & 5 & 2 & 18 \\
\hline tidak tau & 0 & 0 & 18 \\
\hline
\end{tabular}

\section{Kondisi Ekosistem Mangrove}
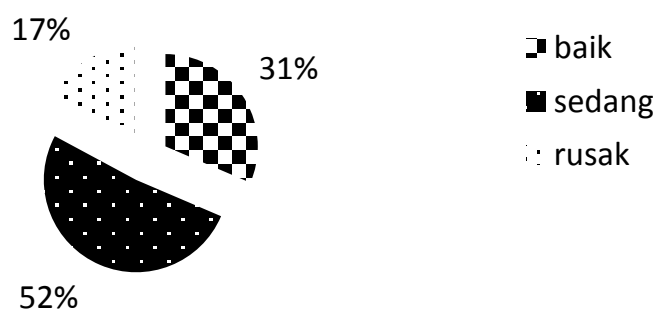

Gambar 2. Persepsi Responden Terhadap Kondisi Ekosistem Mangrove

Dari persentase persepsi responden terhadap kondisi ekosistem mangrove di Desa Pasar Ngalam Kabupaten Seluma kondisi ekosistem mangrove sedang ditunjukkan persentase sebesar $52 \%$, baik $31 \%$ dan rusak berkisar $17 \%$, dapat dilihat pada Gambar 2. Dari hasil wawancara yang dilakukan dengan Bapak Suhadianto selaku Kepalaa Desa Pasar Ngalam, bahwasanya ekosistem mangrove yang berada di desa Pasar Ngalam tersebut belum memiliki status perizinan pemanfaatan dan pencegahan kerusakan ekosistem mangrove, baik peraturan desa maupun peraturan adat. Program rehabilitasi atau penanaman bibit mangrove di Desa Pasar Ngalam sudah 
pernah di lakukan oleh Kebun Bibit Rakyat (KBR) tetapi tidak berhasil karena kurangnya partisipasi masyarakat dalam mengambil bagian.

\section{Parameter Kualitas Air}

Pengambilan data vegetasi mangrove dan parameter kualitas air terdiri dari 3 titik sampling. Masing-masing sampling terletak pada koordinat 04 ${ }^{\circ} 03^{\prime} 408^{\prime \prime}$ LS dan $102^{\circ} 24^{\prime} 911^{\prime \prime}$ BT, 04 $03^{\prime} 117^{\prime \prime}$ LS dan $102^{\circ} 24^{\prime} 053^{\prime \prime}$ BT, $04^{\circ} 03^{\prime} 932^{\prime \prime}$ LS dan $102^{\circ} 24^{\prime} 659^{\prime \prime}$ BT.

Jenis mangrove yang paling banyak di temukan di Desa Pasar Ngalam adalah jenis Rhizophora mucronata, dan Bruguiera gimnorrhiza, kedua jenis tersebut di temukan di seluruh stasiun (Putra,2015).

Tingkat kerapatan mangrove di Desa Pasar Ngalam Kabupaten Seluma yang tertinggi terdapat di stasiun 3 yaitu sebesar $833,33 \mathrm{ind} / \mathrm{Ha}$, diikuti dengan stasiun 2 dan 1 sebesar 416,66 ind/Ha dan 300 ind/Ha. Jenis Rhizophora mucronata memiliki nilai kerapatan tertinggi di stasiun 3 sebesar $450 \mathrm{ind} / \mathrm{Ha}$. Nilai kerapatan terkecil pada stasiun 1 yaitu jenis Rhizophora apicullata, Bruguiera gimnorrhiza, Aegyceras corniculatum (L) Blanco, Hibiscus ilicifolius masing-masing sebesar $33,333 \mathrm{ind} / \mathrm{Ha}$. Stasiun 3 yaitu jenis Aegyceras corniculatum (L) Blanco,dan Carbera manghas, masing-masing sebesar 33.333 ind/Ha (Putra, 2015).

Hasil pengukuran parameter kondisi lingkungan yang terdiri dari salinitas, $\mathrm{pH}$, dan suhu dapat dilihat pada Tabel 5. Dimana pada titik sampling penelitian, memiliki kisaran suhu antara $32{ }^{\circ} \mathrm{C}-34{ }^{\circ} \mathrm{C}$, kisaran ini masih dalam toleransi mangrove, karena mangrove merupakan tumbuhan khas pantai daerah tropis yang hidup pada temperatur dari $19-40{ }^{\circ} \mathrm{C}$ dengan toleransi fluktuasi suhu tidak lebih dari $10{ }^{\circ} \mathrm{C}$ (Irwanto, 2006 dalamPratiwi, 2014). Kusuma (1993) menyatakan bahwa pertumbuhan mangrove yang baik memerlukan suhu ratarata minimal lebih besar dari $20^{\circ} \mathrm{C}$ dan perbedaan suhu musiman tidak melebihi $5{ }^{\circ} \mathrm{C}$.

Menurut Efendi (2003) dalam Putra (2015), salinitas menggambarkan padatan total di dalam air, setelah semua karbonat dikonversi mejadi oksida, semua bromida dan iodida digantikan oleh klorida, dan semua bahan organik telah dioksidasi. Hasil pengukuran salinitas pada setiap titik sampling di ekosistem mangrove Desa Pasar Ngalam Kabupaten Seluma, berkisar antara $6 \%-15 \%$. Tumbuhan mangrove tumbuh subur di daerah estuari dengan salinitas 10 - 30 ppt (Aksornkoae,1993)

Tabel 5. Data Pengukuran Kualitas Air

\begin{tabular}{cccccc}
\hline & & \multicolumn{3}{c}{ Sampling } & Rata-rata \\
\cline { 3 - 5 } No & Parameter & 1 & 2 & 3 & \\
\hline 1 & Temperatur & $34^{\circ} \mathrm{C}$ & $31^{\circ} \mathrm{C}$ & $32{ }^{\circ} \mathrm{C}$ & $35,33^{\circ} \mathrm{C}$ \\
2 & Salinitas & $7 \% 0$ & $6 \% 0$ & $15 \% 0$ & $9,33 \% \circ$ \\
3 & $\mathrm{pH}$ & 8,5 & 8,1 & 8,0 & 8,33 \\
\hline
\end{tabular}

Sumber: Hasil Pengukuran di Lapangan 


\section{Nilai Ekonomi Ekosistem Mangrove}

Identifikasi manfaat dan fungsi ekosistem mangrove di Desa Pasar Ngalam Kabupaten Seluma, dikelompokkan menjadi 4 kategori manfaat, yaitu: manfaat langsung, manfaat tidak langsung, manfaat pilihan dan manfaat eksistensi.

\section{Nilai Manfaat Langsung}

Berdasakan hasil identifikasi, manfaat langsung dari ekosistem mangrove di Desa Pasar Ngalam Kabupaten Seluma yang dapat langsung di rasakan manfaatnya ialah manfaat penangkapan hasil perikanan yakni, kepiting, udang dan ikan. Responden yang berprofesi sebagai nelayan, menangkap hasil perikanan tangkap di sekitar daerah ekosistem mangrove.

Berdasarkan hasil analisis nilai manfaat langsung ekosistem mangrove di Desa Pasar Ngalam Kabupaten Seluma diperoleh nilai sebesar Rp. 328.692.000.-/tahun atau Rp. 42.140.000,-/Ha/tahun. Hal ini berbeda dengan penelitian Suzana $d k k$, (2011) manfaat langsung perikanan tangkap Di Desa Pales, Kecamatan Lingkupang Barat, Kabupaten Minahasa adalah Rp. 175.293.000,-/thn atau sekitar Rp. 570.987,-/Ha/Tahun. Disana terlihat bahwasanya manfaat langsung di Desa Pasar Ngalam Kabupaten Seluma lebih besar dibandingkan manfaat langsung di Desa Pales, Kecamatan Lingkupang Barat. Perbedaan ini dikarenakan adanya perbedaan harga jual perikaan tangkap di Desa Pasar Ngalam Kabupaten Seluma dan perikanan tangkap di Desa Pales Kecamatan Lingkupang Barat. Hasil identifikasi manfaat langsung perikanan tangkap Di Desa Pasar Ngalam dapat dilihat pada Tabel 6, dan persentase dari manfaat langsung perikanan tangkap dapat dilihat pada gambar 3.

Tabel. 6 Manfaat langsung perikanan tangkap

\begin{tabular}{lrcr}
\hline Jenis Manfaat & $\begin{array}{c}\text { Jumlah } \\
\text { Total/tahun (Rp) }\end{array}$ & $\begin{array}{c}\text { Rata-Rata/ } \\
\text { tahun (Rp) }\end{array}$ & $\begin{array}{c}\text { Jumlah } \\
\text { Total/Ha/Tahun } \\
(\mathbf{R p})\end{array}$ \\
\hline Udang & 127.200 .000 & 12.720 .000 & 16.307 .692 \\
ikan & 109.992 .000 & 21.998 .400 & 14.101 .538 \\
kepiting & 91.500 .000 & 4.575 .000 & 11.730 .769 \\
Jumlah & 328.692 .000 & & 42.140 .000 \\
\hline
\end{tabular}

Sumber: Data Primer

\section{Manfaat Langsung}

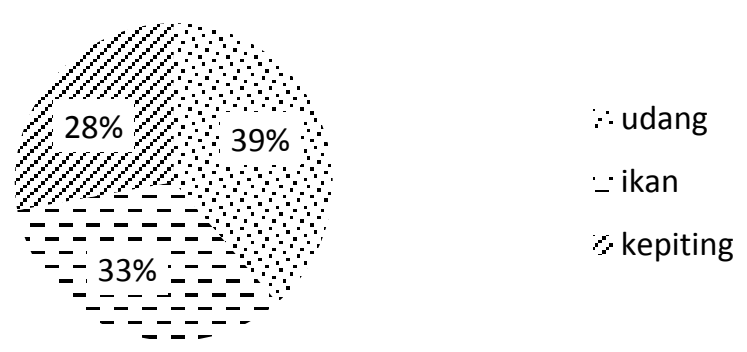

Gambar 3. Grafik pemanfaatan ekosistem mangrove secara langsung 
Grafik diatas menunjukkan bahwa manfaat langsung pencari kepiting memiliki presentase yang lebih rendah dibandingkan dengan manfaat langsung hasil perikanan tangkap lainnya. manfaat pencari kepiting memiliki presentase sebesar $28 \%$ yang memiliki nilai sebesar Rp. 91.500.000,-/tahun atau Rp. 11.730.769,-/Ha/tahun. Nilai ini diperoleh dari penjumlahan rata-rata pendapatan bersih yang diperoleh 20 penangkap kepiting dalam waktu satu tahun. Rata-rata pendapatan hasil tangkapan pencari kepiting sebesar Rp. 71.250,-/ 1 kali penangkapan, dalam sekali penangkapan responden rata-rata mendapatkan 4 kg kepiting dengan harga Rp. 25.000,-/Kg - Rp. 80.000,-/Kg.

\section{Nilai Manfaat Tidak Langsung}

Manfaat tidak langsung dari ekosistem hutan mangrove di Desa Pasar Ngalam Kabupaten Seluma berupa manfaat fisik. Manfaat fisik ini berupa manfaat ekosistem mangrove sebagai pelindung daratan dari ancaman abrasi dan banjir yang disebabkan oleh gemburan ombak dan aliran muara sungai yang ada di Desa Pasar Ngalam. Nilai manfaat ekosistem mangrove sebagai penahan abrasi dan banjir tidak dapat diukur dengan nilai pasar sehingga untuk megukur nilannya dilakukan dengan pendekatan biaya pembuatan penahan ombak (Marhayanadkk, 2012).

Berdasarkan hasil wawancara yang dilakukan dengan salah satu warga yang bekerja di Dinas Pekerjaan Umum Provinsi Bengkulu, biaya yang diperlukan untuk membuat penahan abrasi dan banjir dengan volume $1 \mathrm{~m}^{3}$ adalah \pm Rp. 1.313.915,- dengan asumsi daya tahan selama 10 tahun, sedangkan berdasarkan keterangan dari hasil wawancara dengan PNS di Kabupaten Mukomuko yang pernah menjadi staf Dinas Pekerjaan Umum Kabuapten Mukomuko dan Kepala Bagian Penyusunan Program (SUNRAM) Sekretariat Daerah Kabupaten Muko-muko, biaya untuk pembuatan bangunan penahan abrasi dan banjir dengan volume $1 \mathrm{~m} 3$ adalah $\pm \mathrm{Rp}$. 1.500.000,(Ta'alidin $d k k, 2013$ ). Panjang garis pantai yang terdapat di ekosistem mangrove di Desa Pasar Ngalam sekitar $1.470 \mathrm{~m}$. Jika kebutuhan bangunan penahan abrasi dan banjir dengan tinggi $2 \mathrm{~m}$ dan lebar $1 \mathrm{~m}$ berarti volume bangunan adalah $1.470 \mathrm{~m} \times 2 \mathrm{~m} \times 1 \mathrm{~m}$, maka biaya yang dibutuhkan untuk membuat penahan abrasi dan banjir dengan volume $2.940 \mathrm{~m}^{3}$ sebanyak $\mathrm{Rp}$. 3.862.910.100,- dengan asumsi daya tahan 10 tahun. Untuk daya tahan dalam kurun waktu 1 tahun dibutuhkan biaya sebesar Rp. 386.291.010,--. Jadi manfaat ekosistem mangrove yang dirasakan secara tidak langsung memiliki nilai sebesar Rp. 386.291.010,-/ tahunatau sebesar Rp. 262.783,-/meter/tahun.

\section{Nilai Manfaat Pilihan}

Manfaat pilihan ekosistemmangrove di Desa Pasar Ngalam Kabupaten Seluma dihitung dari manfaat keanekaragaman hayati (biodiversity). Menunut Ruitenbeek (1991) bahwa nilai biodiversity di Indonesia adalah US\$ $1.500 / \mathrm{km}^{2} /$ tahun dengan nilai tukar rupiah terhadap dolar yaitu Rp. 13.017,(oktober 2016), maka diperoleh nilai sebesar Rp. 195.255,-/Ha/Tahun kemudian dikalikan dengan luas ekosistem mangrove seluas $7,8 \mathrm{Ha}$. Jadi nilai manfaat pilihan ekosistem mangrove di Desa Pasar Ngalam Kabupaten Seluma saat ini adalah Rp. 1.522.989,-/tahun. 


\title{
Nilai Eksistensi
}

Manfaat keberadaan ialah suatu nilai yang menunjukkan kesediaan seseorang untuk membayar (Wiling To Pay)guna melestarikan ekosistem mangrove bagi pemanfaatan dimasa yang akan datang. Nilai manfaat ini didekati dengan CVM (Contigent Valuation Method). Penting tidaknya keberadaan ekosistem mangrove dapat ditunjukkan pada tabel 9 berikut.

Tabel 7. Keberadaan Ekosistem Mangrove

\begin{tabular}{ccc}
\hline $\begin{array}{c}\text { Pentingnya keberadaan } \\
\text { mangrove }\end{array}$ & Nelayan & Non Nelayan \\
\hline Penting & 23 & 5 \\
Tidak penting & 0 & 0 \\
Biasa & 0 & 12 \\
\hline
\end{tabular}

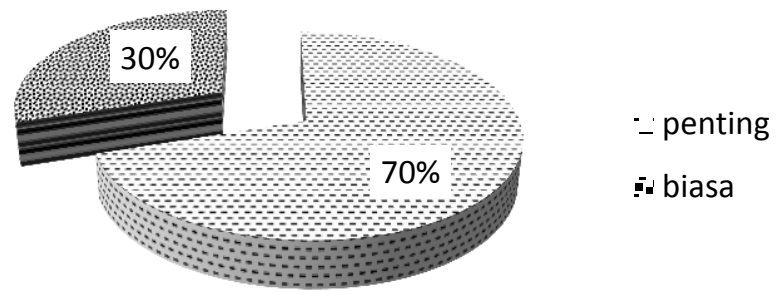

Gambar 4. Grafik Persepsi Responden Terhadap Perlindungan Mangrove

Dari grafik di atas menggambarkan bahwa sebagian besar responden berpendapat perlindungan mangrove itu sangat penting. Hal ini dapat ditunjukkan dengan besarnya persentase yang menganggap pentingnya ekosistem mangrove sebesar $70 \%$ dan $30 \%$ yang beranggapan biasa.

Manfaat keberadaan (eksistensi) dari hutan mangrove Desa Pasar Ngalam Kabupaten Seluma dihitung dengan menggunakan pendekatan CVM (Contigen Valuation Method). Nilai rataan WTP (Willing To Pay) yang diperoleh dari 40 responden yaitu sebesar $\mathrm{Rp}$. 3.300.000,-/tahun atau sebesar Rp. 423.077,-/Ha/Tahun. Rata-rata masing-masing responden ingin membayar sebesar Rp. 82.500,-/tahun.

\section{WTP Nelayan}

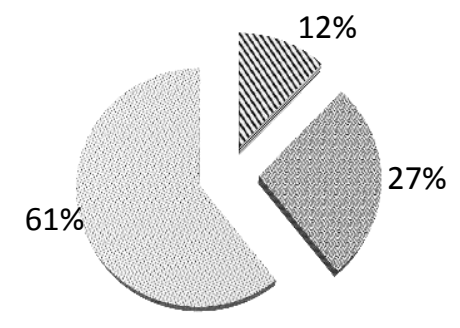

\author{
\26000-50000 \\ ^52000-75000 \\ $\therefore 76000-100000$
}

Gambar 5. Grafik WTP Nelayan Untuk 1 Tahun

Pada grafik di atas menggambarkan WTP terhadap responden yang berprofesi sebagai nelayan. Ketersedian para nelayan untuk membayar dalam 1 tahun kisaran antara Rp. 0,- sampai Rp. 25.000,- sebesar $0 \%$, kisaran antara 
Rp. 26.000,- sampai Rp. 50.000,- sebesar 12\%, kisaran antara Rp. 52.000,sampaiRp. 75.000 ,- sebesar $27 \%$ dan kisaran antara Rp. 76.000,- sampai Rp. 100.000,- sebesar $61 \%$.

\section{WTP non nelayan}

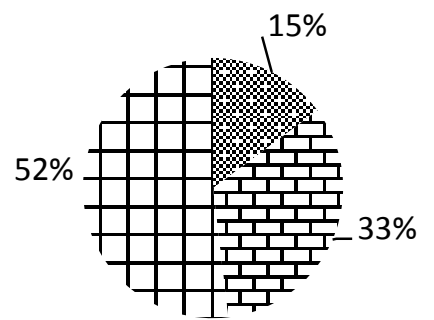

$26000-50000$

¿ 52000-75000

$+76000-100000$

Gambar 6. Grafik WTP Non Nelayan Untuk 1 Tahun

Responden yang berprofesi sebagai bukan nelayan untuk membayar, ditunjukkan pada grafik di atas, di mana responden yang bersedia untuk membayar kisaran Rp. 0,- samapi Rp. 25.000,- sebesar 0\%, kisaran Rp. 26.000,- sampai Rp. 50.000,- sebesar 15\%, kisaran Rp. 52.000,- sampai Rp. 75.000,- sebesar 33\% dan kisaran Rp. 76.000,- sampai Rp. 100.000 sebesar $52 \%$.

\section{Nilai Total Ekonomi Ekosistem Mangrove}

Hasil identifikasi manfaat langsung, manfaat tidak langsung, manfaat pilihan dan manfaat eksisteni yang ada di Desa Pasar Ngalam Kabupaten Seluma yang dikuantifikasikan ke dalam nilai rupiah maka diperoleh nilai total dari keseluruhan manfaat tersebut sebesar Rp. 719.805.999,-/ tahunnya atau sebesar Rp. 92.282.820,-/Ha/tahun.

Nilai ekonomi berikutnya adalah manfaat langsung dimana manfaat ini memiliki presentase sebesar $45.29 \%$ dengan nilai $\mathrm{Rp}$. 328,692,000 tidak jauh perbedaannya dengan manfaat tidak langsung karna hasil perikanan tangkap di Desa Pasar Ngalam Kabupaten Seluma merupakan penopang hidup bagi masyarakat yang berprofesi sebagai nelayan.

Nilai ekonomi manfaat pilihan dan nilai manfaat eksistensi pilihan memiliki presentase sebesar 0,21\% dan 0,45\%. Ekosistem mangove sebagai suatu keanekaragaman hayati yang dinilai sebesar US $\$ 15 /$ ha/tahun, dengan luas mangrove sekitar $7,8 \mathrm{Ha}$, ternyata memiliki nilai yang relatif kecil yaitu sebesar Rp. 1.522.989,-/tahun.

Dari perhitungan seluruh nilai manfaat ekosistem mangrove, maka nilai manfaat total ekosistem mangrove di Desa Pasar Ngalam Kabupaten Seluma memiliki nilai yang relatif kecil dibandingkan dengan nilai keseluruhan manfaat total ekosistem mangrove di Desa Pasar Sebelah Kabupaten Mukomuko. Nilai manfaat total di Desa Pasar Ngalam Kabupaten Seluma memiliki nilai sebesar Rp. 18.942.263,-/ha/tahun,

Perbedaan nilai yang terjadi pada masing-masing penelitian yang sejenis antara lain adanya perubahan nilai tukar rupiah terhadap US\$, luasan ekosistem mangrove, perbedaan harga, dan keanekaragaman pemanfaatan yang dilakukan oleh masyarakat setempat. Paryono (1999) mengidentifikasi pemanfaatan yang ada di Segara Anakan meliputi potensi kayu, pemanfaatan 
kayu bakar, daun nipah, arang, bibit bakau, kepiting, udang, ikan, kerang, tambak, dan wisata. Manfaat langsung yang didapatkan lebih kecil daripada manfaat tidak langsung disebabkan karena besarnya nilai manfaat ekologis ekosistem mangrove sebagai pencegah intruisi air laut dan manfaat biologis sebagai penjaga kestabilan pakan ikan.

\section{KESIMPULAN}

Hasil penelitin Valuasi Ekonomi Ekosistem Mangrove Di Desa Pasar Ngalam Kabupaten Seluma dapat disimpulkan bahwa:

1. Manfaat ekosistem mangrove di DesaPasar Ngalam Kabupaten Seluma terdiri dari manfaat langsung berupa penangkapan ikan, kepiting dan udang, manfaat tidak langung berupa penahan abrasi, manfaat pilihan berupa nilai keanekaragaman hayati, dan manfaat eksistensi berupa nilai yang diberikan masyarakat terkait ekosistem mangrove di Desa Pasar Ngalam.

2. Nilai manfaat total ekonomi ekosistem mangrove di Desa Pasar Ngalam Kabupaten Seluma adalah sebesar Rp. 719.805.999,-/tahun terdiri dari manfaat langsung sebesar Rp. 328.692.000/ tahun (45,29\%), manfaat tidak langsung sebesar Rp. 386.291.010,-/tahun (53,32\%), manfaat pilihan sebesar Rp. 1.522.989,-/tahun (0,21\%), dan manfaat eksistensi sebesar Rp. 3.300.000,-/tahun (0,45\%). Berdasarkan perhitungan nilai manfaat total ekonomi ekosistem mangrove di Desa Pasar Ngalam Kabupaten Seluma dapat dikategorikan nilai ekonomi ekosistem mangrove yang tinggi.

\section{DAFTAR PUSTAKA}

Aksornkoae, S. 1993. Ecology and Management of Mangrove. IUCN, Bangkok. Thailand.

Badan Konservasi Sumberdaya Alam Bengkulu. 2013. Konservasi Kawasan Cagar Alam Pasar Ngalam. Hhtp://bksdabengkulu.org/. Diakses tanggal 2 Mei 2016.

Fahrudin, A. 1997. Analisis Ekonomi Pengelolaan Lahan Pesisir Kabupaten Subang, Jawa Barat. [Tesis]. Bogor. Program Pasca Sarjan. Institut Pertanian Bogor.

FAO. Management and Utilization of mangroves in Asia Pasific. FAO Environmental Paper 3, FAO, Rome. 1983 Hutching, P and P.Saenger. Ecology of Mangroves.

Kusmana, C. 2009. Pengelolaan sistem Mangrove Secara Terpadu. Jawa Barat. $22 \mathrm{hlm}$.

Marhayana, S., Niartiningsih,A., Idrus, R. 2012. Manfaat Ekonomi Ekosistem Mangrove di Taman Wisata Perairan Padaido Kabupaten Biak Numfor, Papua. Fakultas IImu Kelautan dan Perikanan Universitas Hasanudin, Makassar.

Paryono, TJ. 1999. Kajian Pengelolaan Ekonomi Ekositem Mangrove di Kawasan Segara Anakan, Kabupaten Cilacap, Jawa Tengah [Tesis]. Bogor : IPB, Program Pasca Sarjana. 
Pomeroy, R.S. 1992. Economic Valuation Available Methode. P. 149-162. In T.E Chua and LF Scura (eds.) Integrative framwork and methodes for coastal area management. ICLARM Contf.Proc, 37,169p.

Putra, R.E. 2015. Struktur Komunitas Ekosistem Mangrove di Sungai Sindur Pasar Ngalam Seluma [Skripsi]. Bengkulu. Program Sarjana. Universitas Bengkulu.

Ta'aladin, Z., D Bakhtiar., D Purnama. 2012. Kajian Karakteristik Ekososionik Wilayah Pesisir Dalam Upaya Pelestarian Ekosistem Hutan Mangrove di Kabupaten Mukomuko. Laporan Penelitian Fundamental Tahun 2012. Lembaga Penelitian UNIB, Bengkulu.

Zen, L.W., Ulfah, F. 2013. Valuasi Ekonomi Hutan Mangrove Di Pulau Dompak Kota Tanjung Pinang Provinsi Kepulauan Riau. Jurusan Manajemen Sumberdaya Perairan Universitas Maritim Jaya Ali Haji. Tanjung Pinang. Jurnal Dinamika Maritim 4 (1) : 45-52. 